\title{
PENGARUH KEDISIPLINAN DAN KOMPENSASI TERHADAP KINERJA KARYAWAN PADA PT. MITRA PINANTHIKA MUSTIKA RENT DI TANGERANG
}

\author{
Iis Noviyanti ${ }^{1}$, Apriyani Suci Ramadan ${ }^{2}$ \\ Fakultas Ekonomi, Universitas Pamulang \\ Email: dosen01107@unpam.ac.id¹, Apriyani.suci@mpm-rent.com²
}

\begin{abstract}
Purpose. This study aims to determine the effect of discipline and compensation on employee performance at PT. Mitra Pinathika Mustika Rent in Tangerang.

Methods. The method used is descriptive method with an associative approach, while to obtain data is done by distributing questionnaires to 100 respondents and analyzed by regression, correlation, determination and hypothesis testing.

Findings. The results of disciplinary research have a positive and significant effect on employee performance by 33.5\%. Hypothesis testing obtained $t$ value $>t$ table (7.029>1.984), this is also reinforced by a significance probability of $0.000<0.05$. Thus $\mathrm{HO}$ is rejected and $\mathrm{H1}$ is accepted, meaning that there is an influence of discipline on employee performance. Compensation has a positive and significant effect on employee performance by $41.4 \%$. Hypothesis test obtained $t$ value $>t$ table (8.325> 1.984), this is also reinforced by a significance probability of $0.000<0.05$. Thus, $\mathrm{HO}$ is rejected and H1 is accepted, meaning that there is an effect of compensation on employee performance. Discipline and compensation simultaneously have a positive and significant effect on employee performance with the regression equation $Y=11.712+0.270 X 1+0.448 X 2$. The correlation value obtained is 0.694 and the influence contribution is $48.2 \%$, while the remaining $51.8 \%$ is influenced by other factors. Hypothesis test obtained $F$ count $>F$ table $(45,100>3,090)$ this is reinforced by $F$ Probability significance 0,000 $<0.05$, thus $\mathrm{HO}$ is rejected and H3 is accepted, meaning that there is a positive and significant influence between Discipline and Compensation simultaneously on the performance of PT employees. Mitra Pinathika Mustika Rent in Tangerang.
\end{abstract}

Implication. Companies must raise awareness among all employees in order to have an optimal work ethic. The company must provide bonuses based on the agreement in the company rules. The company must improve the infrastructure in the company in order to be able to increase the maximum performance.

Keywords. Discipline, Compensation, and Employee Performance.

\begin{abstract}
ABSTRAK
Tujuan. Penelitian ini bertujuan untuk mengetahui pengaruh kedisiplinan dan kompensasi terhadap kinerja karyawan pada PT. Mitra Pinathika Mustika Rent di Tangerang.

Metode. Metode yang digunakan adalah metode deskriptif dengan pendekatan asosiatif, sedangkan untuk mendapatkan data dilakukan dengan menyebar kuesioner kepada 100 responden dan di analisis dengan regresi, korelasi, determinasi dan uji hipotesis.
\end{abstract}


Hasil. Hasil penelitian kedisiplinan berpengaruh positif dan signifikan terhadap kinerja karyawan sebesar 33,5\%. Uji hipotesis diperoleh nilai $t$ hitung $>t$ tabel $(7,029>1,984)$, hal ini juga diperkuat dengan probability signifikansi $0,000<0,05$. Dengan demikian $\mathrm{H}_{0}$ ditolak dan $\mathrm{H}_{1}$ diterima artinya terdapat pengaruh Kedisiplinan terhadap kinerja karyawan. Kompensasi berpengaruh positif dan signifikan terhadap kinerja karyawan sebesar 41,4\%. Uji hipotesis diperoleh nilai t hitung $>t$ tabel $(8,325>1,984)$, hal ini juga diperkuat dengan probability signifikansi $0,000<0,05$. Dengan demikian $\mathrm{H}_{0}$ ditolak dan $\mathrm{H}_{1}$ diterima artinya terdapat pengaruh kompensasi terhadap kinerja karyawan. Kedisiplinan dan kompensasi secara simultan berpengaruh positif dan signifikan terhadap kinerja karyawan dengan persamaan regresi $\mathrm{Y}=11,712+0,270 \mathrm{X}_{1}+0,448 \mathrm{X}_{2}$. Nilai korelasi diperoleh sebesar 0,694 dan kontribusi pengaruhnya sebesar 48,2\% sedangkan sisanya sebesar $51,8 \%$ dipengaruhi faktor lain. Uji hipotesis diperoleh $F_{\text {hitung }}>F_{\text {tabel }}(45,100>$ 3,090 ) hal ini diperkuat dengan F-Probability signifikansi $0,000<0,05$, dengan demikian $\mathrm{H}_{0}$ ditolak dan $\mathrm{H}_{3}$ diterima artinya terdapat pengaruh positif dan signifikan antara Kedisiplinan dan Kompensasi secara simultan terhadap kinerja karyawan PT. Mitra Pinathika Mustika Rent di Tangerang.

Implikasi. Perusahaan harus menumbuhkan kesadaran pada seluruh karyawan agar memiliki etos kerja yang optimal. Perusahaan harus memberikan bonus berdasar pada kesepakatan dalam aturan perusahaan. Perusahaan harus meningkatkan sarana prasarana dalam perusahaan agar mampu meningkatkan kinerja yang maksimal.

Kata Kunci. Kedisiplinan, Kompensasi, dan Kinerja Karyawan.

\section{Pendahuluan}

Manajemen adalah ilmu dan seni mengatur proses pemanfaatan sumber daya manusia dan sumber-sumber daya lainnya secara efektif dan efisien untuk mencapai suatu tujuan tertentu. Manajemen ini terdiri dari enam unsur (6 M), yaitu :men, money, method, materials, machines, dan market. Menurut H. Malayu S.P Hasibuan (2012 : 10) Manusia selalu berperan aktif dan dominan dalam setiap kegiatan organisasi, karena manusia menjadi perencana, pelaku dan penentu terwujudnya tujuan organisasi. Tujuan tidak mungkin terwujud tanpa peran aktif karyawan meskipun alat-alat yang dimiliki perusahaan begitu canggihnya.Namun SDM yang mampu dan terampil, cekatan, belum menjamin produktivitas kerja yang baik, kalau moral dan kedisiplinannya rendah.

Disiplin yang baik mencerminkan besarnya rasa tanggung jawab seseorang terhadap tugas-tugas yang diberikan kepadanya.Hal ini mendorong gairah kerja, semangat kerja, dan terwujudnya tujuan perusahaan, karyawan dan masyarakat.Kedisiplinan adalah kesadaran dan kesediaan seseorang menaati semua peraturan perusahaan dan norma-norma sosial yang berlaku. Perusahaan dan karyawan pada hakekatnya saling membutuhkan, dengan adanya sumber daya manusia tentu akan mampu meningkatkan kinerja karyawan yang lebih baik bagi perusahaan. Dalam meningkatkan dan mempertahankan kinerja karyawan, dapat dilakukan dengan cara pelatihan (training) dan pendidikan, mengevaluasi kinerja karyawan, pemberian kompensasi yang layak dan menciptakan suasana kerja yang kondusif. Karena itu perusahaan harus tetap mempertahankan karyawan yang memiliki loyalitas yang tinggi terhadap perusahaan dengan memberikan gaji/ kompensasi/ upah, yang diharapkan dapat memicu karyawan ke arah peningkatan kinerja karyawan.

Kompensasi adalah apa yang seorang pekerja terima sebagai balasan dari pekerjaan yang diberikannya. Baik upah per jam ataupun gaji periodik didesain dan dikelola oleh bagian personalia (William B dan Keith Davis, dalam buku Hasibuan 2012 : 119). Tetapi jika para karyawan memandang kompensasi mereka tidak memadai, prestasi kerja, motivasi, dan kepuasan kerja para karyawan bisa menurun secara drastis. Oleh karena itu, bila kompensasi diberikan diberikan secara benar, para karyawan akan lebih termotivasi dan terpuaskan untuk mencapai sasaran yang ditetapkan perusahaan. Dalam penelitian ini mengambil satu jenis kompensasi yaitu pembayaran langsung berbentuk materi (financial) yang disebut upah/ gaji. 
Selain kompensasi, faktor kedisiplinan memegang peranan sangat penting dalam pelaksanaan kerja karyawan. Seorang karyawan yang mempunyai tingkat kedisiplinan yang tinggi akan tetap bekerja dengan baik tanpa diawasi atasan. Disiplin kerja adalah suatu alat yang digunakan para manajer untuk berkomunikasi dengan karyawan agar mereka besedia untuk mengubah suatu perilaku serta suatuupaya untuk meningkatkan kesadaraan dan kesediaan seseorang menaati semua peraturan perusahaan dan norma-norma sosial yang berlaku. Dengan adanya pemberian kompensasi yang sesuai dan kedisiplinan kerja yang meningkat maka kinerja karyawan akan lebih baik dan efektif. Kinerja sebagai kemajuan dan tingkat penyelesaian suatu pekerjaan baik kualitas maupun kuantitasnya yang harus meningkat dari waktu ke waktu. Menurut Moeheriono (2012:95), kinerja atau performance merupakan gambaran mengenai tingkat pencapaian pelaksanaan suatu program kegiatan atau kebijakan dalam mewujudkan sasaran, tujuan, visi dan misi organisasi yang dituangkan melalui perencanaan strategis suatu organisasi. Namun beberapa faktor yang dapat menurunkan kinerja karyawan, diantaranya menurunannya keinginan karyawan untuk mencapai prestasi kerja, kurangnya ketepatan waktu dalam mengerjakan pekerjaan sehingga tidak menaati peraturan, faktor lingkungan, kurangnya motivasi, dan tidak sesuainya pemberian kompensasi yang diberikan.Beberapa hal itulah yang dapat menurunkan kinerja karyawan.Untuk itu penulis tertarik melakukan penelitian secara lebih mendalam mengenai kedua variabel tersebut.

Penelitian ini mengambil objek penelitian pada Perusahaan PT Mitra Pinasthika Mustika Rent yang bergerak dalam bidang jasa penyewaan mobil dan jasa driver.Kegiatan yang dilakukan oleh perusahaan ini adalah menawarkan pinjaman/ sewa unit mobil beserta driver kepada user-user yang membutuhkan, ataupun hanya menyewa unit mobil saja untuk kegiatan operasional ataupun sebagai unit remunetion karyawannya. PT Mitra Pinasthika Mustika Rent sangat membutuhkan kedisiplinan dan kinerja karyawan yang tinggi untuk meningkatkan produktivitas karyawan, karena dengan memiliki tanggung jawab yang tinggi, tujuan yang realitas, rencana kerja yang menyeluruh maka produktivitas karyawan akan meningkat, oleh karena itu salah satunya dengan pemberian kompensasi yang sesuai dan tingkat kedisiplinan yang tinggi.

Tabel 1. Data Absensi 100 karyawan PT Mitra Pinasthika Mustika Rent bulan Januari sampai Maret 2017

\begin{tabular}{|l|c|c|c|c|c|c|c|c|}
\hline Bulan & $\begin{array}{c}\text { Sebelum } \\
\text { pukul } \\
08: 01\end{array}$ & $\begin{array}{c}\text { Hadir } \\
\text { antara } \\
\text { pukul } \\
08: 01- \\
08: 05\end{array}$ & $\begin{array}{c}\text { Hadir } \\
\text { diatas } \\
\text { pukul } \\
08: 05\end{array}$ & $\begin{array}{c}\text { Tidak } \\
\text { Absen } \\
\text { Masuk }\end{array}$ & $\begin{array}{c}\text { Tidakada } \\
\text { Keterangan }\end{array}$ & Sakit & Cuti & $\begin{array}{c}\text { Cuti } \\
\text { Melahirkan }\end{array}$ \\
\hline Januari & 45 & 21 & 30 & 0 & 0 & 0 & 1 & 3 \\
\hline Februari & 41 & 22 & 34 & 0 & 1 & 1 & 1 & 1 \\
\hline Maret & 42 & 22 & 34 & 0 & 0 & 1 & 1 & 0 \\
\hline
\end{tabular}

Sumber : PT Mitra Pinasthika

Berdasarkan tabel absensi diatas dapat diketahui bahwa terjadi penambahan rata-rata jumlah karyawan yang hadir diatas pukul 8:05 dari bulan januari sebanyak 30 orang menjadi 34 orang pada bulan februari, sedangkan pada bulan maret tidak terjadi perubahan pada kehadiran karyawan diatas pukul 8:05. Berikut adalah Grafik absensi 100 karyawan PT Mitra Pinasthika Mustika Rent bulan januari sampai maret 2017. 


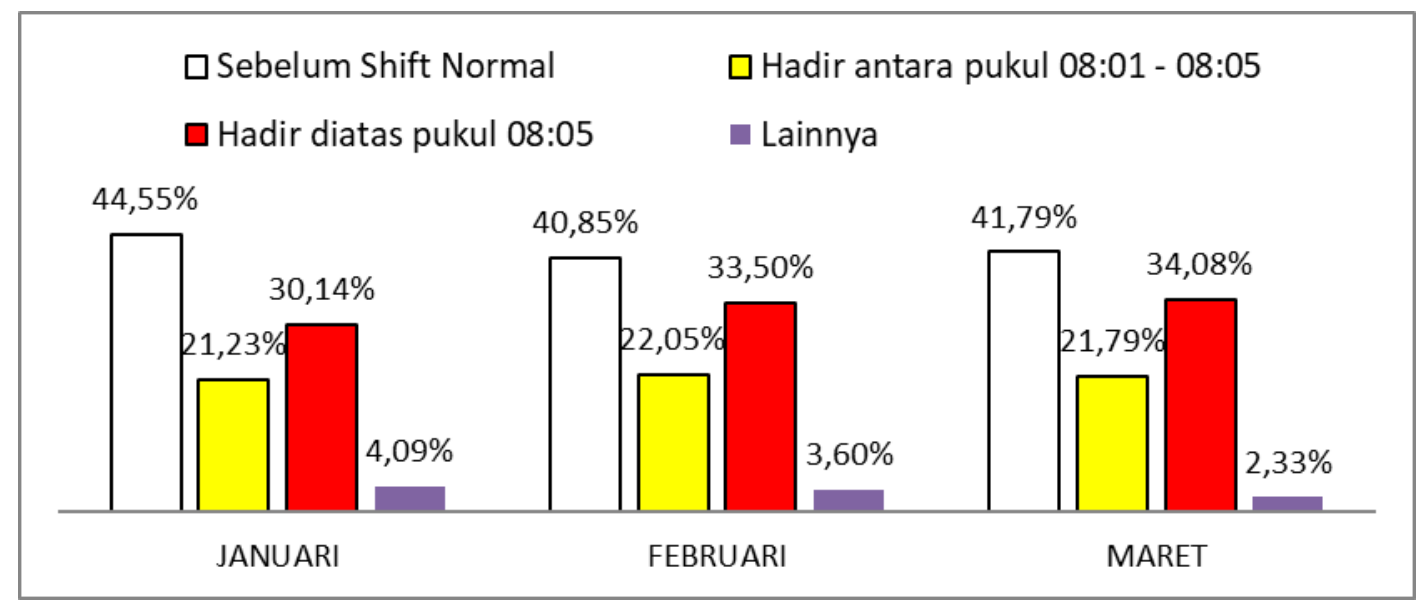

Sumber : PT Mitra Pinasthika

Gambar 1. Grafik absensi PT Mitra Pinasthika Mustika Rent Bulan Januari Maret 2017

Berdasarkan grafik absensi diatas dapat diketahui bahwa :

1) Terjadi penurunan sebanyak $3,68 \%$ rata-rata kehadiran karyawan sebelum shift normal dari bulan januari ke bulan februari. Sedangkan, terjadi peningkatan sebanyak 0,94\% dari bulan februari ke bulan maret.

2) Tidak terjadi perubahan yang signifikan rata-rata kehadiran karyawan untuk shift normal pukul 8:01 - 8:05 dari setiap bulannya..

3) Terjadi peningkatan rata-rata kehadiran karyawan diatas pukul 8:05 untuk setiap bulannya. Pada bulan januari kehadiran karyawan rata-rata 30,14\% , meningkat 3,36\% pada bulan februari dan meningkat $0.58 \%$ pada bulan maret.

Atas dasar latar belakang yang telah diuraikan, maka dilakukan penelitian ini untuk mengetahui bagaimana pengaruh dari pemberian kompensasi financial dan kedisiplinan terhadap kinerja karyawan. Berdasarkan uraian diatas, maka dapat diangkat judul "Pengaruh Kedisiplinan dan Kompensasi Finansial Terhadap Kinerja Karyawan pada PT Mitra Pinasthika Mustika Rent".

\section{Kajian Pustaka dan Hipotesis}

Kedisiplinan. Menurut Rivai (2015:825) “Disiplin kerja adalah suatu alat yang digunakan para manajer untuk berkomunikasi dengan karyawan agar mereka bersedia untuk mengubah suatu perilaku dan untuk meningkatkan kesadaran juga kesediaan seseorang agar mentaati semua peraturan dan norma sosial yang berlaku di suatu perusahaan". Sedangkan menurut Darodjat (2015:95) "Kedisiplinan adalah suatu sikap tingkah laku dan perbuatan yang sesuai dengan peraturan dari perusahaan baik tertulis maupun tidak tertulis".

Kompensasi. Menurut Hasibuan (2016 : 118) "Kompensasi adalah semua pendapatan yang berbentuk uang, barang, langsung atau tidak langsung yang diterima karyawan sebagai imbalan atas jasa yang diberikan kepada perusahaan". Menurut Rivai (2015:714) "Kompensasi merupakan sesuatu yang diterima karyawan sebagai pengganti kontribusi jasa mereka pada perusahaan".

Kinerja Karyawan. Menurut Mangkunegara (2016:67), Pengertian kinerja adalah "hasil kerja secara kualitas dan kuantitas yang dicapai oleh seorang pegawai dalam melaksanakan tugasnya sesuai dengan tanggung jawab yang diberikan kepadanya". Menurut Edison (2016:190), "Kinerja adalah hasil dari suatu proses yang mengacu dan diukur selama periode waktu tertentu berdasarkan ketentuan atau kesepakatan yang telah ditetapkan sebelumnya". 


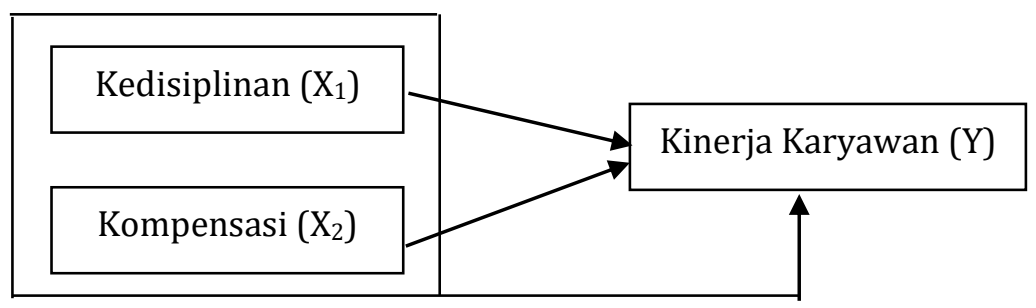

Gambar 2. Model Penelitian

Hipotesis. Menurut Sugiyono (2017:134), "hipotesis merupakan jawaban sementara terhadap rumusan masalah, dimana rumusan penelitian telah dinyatakan dalam bentuk kalimat pernyataan". Dikatakan sementara karena jawaban yang diberikan baru didasarkan pada teori yang relevan, belum didasarkan pada fakta-fakta empiris yang diperoleh melalui pengumpulan data.

$\mathrm{H}_{1}=$ Kedisiplinan berpengaruh positif dan signifikan terhadap kinerja karyawan

$\mathrm{H}_{2}=$ Kompensasi berpengaruh positif dan signifikan terhadap kinerja karyawan

$\mathrm{H}_{3}=$ Kedisiplinan dan Kompensasi berpengaruh positif dan signifikan terhadap kinerja karyawan

\section{Metode Penelitian}

Penelitian ini dilakukan pada PT Mitra Pinathika Mustika Rent, yang beralamat di Sunburst, CBD Lot II No. 10, Jl. Kapten Soebijanto Djojohadikusumo, BSD City, Tangerang 15322. Menurut Etta Mamang Sangadji dan Sopiah (2010:154), populasi adalah wilayah generalisasi yang terdiri atas subyek dengan kualitas dan karakteristik tertentu yang ditetapkan oleh peneliti untuk dipelajari dan kemudian ditarik kesimpulan.Populasi bisa berupa subyek atau obyek penelitian. Populasi dalam penelitian ini adalah seluruh karyawan PT MPM Rent yang berjumlah 100 Karyawan. jumlah responden yang akan dijadikan sampel penelitian adalah sebanyak 100 orang.

\section{Hasil Penelitian dan Pembahasan Pengujian Validitas}

Tabel 2. Hasil Uji Validitas

\begin{tabular}{|c|c|c|c|c|c|}
\hline Pernyataan & $\begin{array}{c}\text { Nilai } \\
\text { Rhitung } \mathbf{X}_{\mathbf{1}}\end{array}$ & $\begin{array}{c}\text { Nilai } \\
\text { Rhitung } \mathbf{X}_{\mathbf{2}}\end{array}$ & $\begin{array}{c}\text { Nilai } \\
\text { Rhitung Y }\end{array}$ & $\begin{array}{c}\text { Nailai } \\
\mathbf{r}_{\text {tabel }}\end{array}$ & Keputusan \\
\hline Pernyataan 1 & 0.384 & 0.418 & 0.442 & 0,196 & Valid \\
\hline Pernyataan 2 & 0.368 & 0.576 & 0.551 & 0,196 & Valid \\
\hline Pernyataan 3 & 0.379 & 0.435 & 0.416 & 0,196 & Valid \\
\hline Pernyataan 4 & 0.501 & 0.525 & 0.496 & 0,196 & Valid \\
\hline Pernyataan 5 & 0.779 & 0.564 & 0.469 & 0,196 & Valid \\
\hline Pernyataan 6 & 0.488 & 0.394 & 0.499 & 0,196 & Valid \\
\hline Pernyataan 7 & 0.742 & 0.646 & 0.641 & 0,196 & Valid \\
\hline Pernyataan 8 & 0.790 & 0.444 & 0.526 & 0,196 & Valid \\
\hline Pernyataan 9 & 0.783 & 0.463 & 0.662 & 0,196 & Valid \\
\hline Pernyataan 10 & 0.507 & 0.611 & 0.483 & 0,196 & Valid \\
\hline
\end{tabular}

Sumber : Data diolah (2020)

Dari data tabel di atas, variabel kedisiplinan, kompensasi dan kinerja karyawan diperoleh nilai rhitung lebih besar dari 0,196, maka semua item pernyataan dinyatakan valid. Untuk itu kuesioner yang digunakan layak untuk diolah sebagai data penelitian. 


\section{Pengujian Reliabilitas}

Tabel 3. Hasil Uji Reliabilitas

\begin{tabular}{|l|c|c|c|}
\hline \multicolumn{1}{|c|}{ Variabel } & $\begin{array}{c}\text { Chronbatch } \\
\text { Alpha }\end{array}$ & $\begin{array}{c}\text { Standar } \\
\text { Chronbatch Alpha }\end{array}$ & Keputusan \\
\hline Kedisiplinan $\left(\mathrm{X}_{1}\right)$ & 0.764 & 0.600 & Reliabel \\
\hline Kompensasi $\left(\mathrm{X}_{2}\right)$ & 0.683 & 0.600 & Reliabel \\
\hline Kinerja Karyawan $(\mathrm{Y})$ & 0.699 & 0.600 & Reliabel \\
\hline
\end{tabular}

Sumber : Data diolah (2020)

Berdasarkan tabel di atas, menunjukkan bahwa semua item pertanyaan variabel kedisiplinan $\left(\mathrm{X}_{1}\right)$, kompensasi $\left(\mathrm{X}_{2}\right)$ dan kinerja karyawan $(\mathrm{Y})$, dinyatakan reliabel, hal itu dibuktikan dengan nilai Chronbatch Alpha $>0,60$.

\section{Asumsi Klasik \\ Normalitas Data}

\begin{tabular}{|c|c|c|c|c|c|c|}
\hline \multicolumn{7}{|c|}{$\begin{array}{l}\text { Tabel 4. Hasil Uji Normalitas } \\
\text { Tests of Normality }\end{array}$} \\
\hline & \multicolumn{3}{|c|}{ Kolmogorov-Smirnova } & \multicolumn{3}{|c|}{ Shapiro-Wilk } \\
\hline & Statistic & $\mathrm{df}$ & Sig. & Statistic & $\mathrm{df}$ & Sig. \\
\hline Kinerja Karyawan (Y) & .086 & 100 & .068 & .978 & 100 & .094 \\
\hline
\end{tabular}

*. This is a lower bound of the true significance.

a. Lilliefors Significance Correction

Sumber : Data diolah (2020)

Berdasarkan hasil pengujian pada tabel di atas, diperoleh nilai signifikansi $\alpha=0,200$ dimana nilai tersebut lebih besar dari nilai $\alpha=0,050$ atau $(0,068>0,05)$. Dengan demikian maka asumsi distribusi persamaan pada uji ini adalah normal.

\section{Multikolinearitas}

\section{Tabel 5. Hasil Uji Multikolinearitas \\ Coefficients $^{\mathrm{a}}$}

\begin{tabular}{|c|c|c|c|}
\hline \multirow{2}{*}{\multicolumn{2}{|c|}{ Model }} & \multicolumn{2}{|c|}{ Collinearity Statistics } \\
\hline & & Tolerance & VIF \\
\hline \multirow{3}{*}{1} & (Constant) & & \\
\hline & Kedisiplinan (X1) & .679 & 1.473 \\
\hline & Kompensasi (X2) & 679 & 1.473 \\
\hline
\end{tabular}

a. Dependent Variable: Kinerja Karyawan (Y)

Sumber : Data diolah (2020)

Berdasarkan tabel pengujian multikolinieritas di atas diperoleh nilai Variance Inflation Factor (VIF) masing-masing variabel bebas memiliki nilai toleransi $<1$ dan nilai VIF $<10$, dengan demikian model regresi ini tidak ada multikolinearitas.

\section{Autokorelasi}

\section{Tabel 6. Hasil Uji Autokorelasi} Model Summaryb

\begin{tabular}{ll|r|r|r|r} 
Model & R & R Square & $\begin{array}{c}\text { Adjusted R } \\
\text { Square }\end{array}$ & $\begin{array}{c}\text { Std. Error of } \\
\text { the Estimate }\end{array}$ & Durbin-Watson \\
\hline 1 & $.694^{\mathrm{a}}$ & .482 & .471 & 2.621 & 1.957 \\
\hline
\end{tabular}

a. Predictors: (Constant), Kompensasi (X2), Kedisiplinan (X1)

b. Dependent Variable: Kinerja Karyawan (Y)

Sumber : Data diolah (2020) 
Berdasarkan hasil pengujian pada tabel di atas, model regresi ini tidak ada autokorelasi, hal ini dibuktikan dengan nilai Durbin-Watson sebesar 1.957 yang berada diantara $1.550-2.460$

\section{Heteroskedastisitas}

\begin{tabular}{|c|c|c|c|c|c|c|}
\hline \multirow{3}{*}{\multicolumn{2}{|c|}{ Model }} & \multicolumn{3}{|c|}{ Coefficients ${ }^{\mathbf{a}}$} & \multirow[b]{3}{*}{$\mathrm{t}$} & \multirow[b]{3}{*}{ Sig. } \\
\hline & & \multicolumn{2}{|c|}{$\begin{array}{l}\text { Unstandardized } \\
\text { Coefficients }\end{array}$} & \multirow{2}{*}{$\begin{array}{c}\text { Standardized } \\
\text { Coefficients } \\
\text { Beta }\end{array}$} & & \\
\hline & & $\mathrm{B}$ & Std. Error & & & \\
\hline 1 & (Constant) & .444 & 1.821 & & .244 & .808 \\
\hline & Kedisiplinan (X1) & -.058 & .047 & -.147 & -1.214 & .228 \\
\hline & Kompensasi (X2) & .097 & .053 & .221 & 1.826 & .071 \\
\hline
\end{tabular}

a. Dependent Variable: RES2

Sumber : Data diolah (2020)

Berdasarkan hasil pengujian pada tabel di atas, glejser test model pada variabel kedisiplinan $\left(\mathrm{X}_{1}\right)$ diperoleh nilai probability (Sig.) 0,228 dan kompensasi $\left(\mathrm{X}_{2}\right)$ nilai probability (Sig.) 0,071 dimana keduanya (Sig.) > 0,05. Dengan demikian regression model tidak ada gangguan heteroskesdastisitas, sehingga model regresi ini layak dipakai sebagai data penelitian.

\section{Uji Regensi Linear Berganda}

Tabel 8. Hasil Uji Regresi Linier Berganda Coefficients $^{a}$

Unstandardized Standardized Coefficients Coefficients

\begin{tabular}{|c|c|c|c|c|c|c|}
\hline \multicolumn{2}{|c|}{ Model } & B & Std. Error & Beta & $\mathrm{t}$ & Sig. \\
\hline \multirow[t]{3}{*}{1} & (Constant) & 11.712 & 2.914 & & 4.019 & .000 \\
\hline & Kedisiplinan (X1) & .270 & .076 & .316 & 3.557 & .001 \\
\hline & Kompensasi (X2) & .448 & .085 & .465 & 5.240 & .000 \\
\hline
\end{tabular}

a. Dependent Variable: Kinerja Karyawan (Y)

Sumber : Data diolah (2020)

Berdasarkan hasil perhitungan regresi pada tabel diatas, maka dapat diperoleh persamaan regresinya $\mathrm{Y}=11,712+0,270 \mathrm{X}_{1}+0,448 \mathrm{X}_{2}$. Dari persamaan di atas maka dapat disimpulkan sebagai berikut:

1) Nilai konstanta sebesar 11,712 diartikan bahwa jika variabel $X_{1}$ dan $X_{2}$ tidak ada maka telah terdapat kepuasan pelanggan 11,712 .

2) Nilai 0,270 diartikan apabila konstanta tetap dan tidak ada perubahan pada variabel $\mathrm{X}_{1}$, maka setiap perubahan 1 unit pada variabel $\mathrm{X}_{1}$ akan mengakibatkan terjadinya perubahan pada Y sebesar 0,270 point.

3) Nilai 0,448 diartikan apabila konstanta tetap dan tidak ada perubahan pada variabel $\mathrm{X}_{2}$, maka setiap perubahan 1 unit pada variabel $\mathrm{X}_{2}$ akan mengakibatkan terjadinya perubahan pada Y sebesar 0,448 point.

Uji Koefisien Determinasi

Tabel 9. Hasil Uji Koefisien Determinasi

Model Summary

\begin{tabular}{|c|c|c|c|c|}
\hline \multicolumn{5}{|c|}{ Model Summary } \\
\hline Model & $\mathrm{R}$ & R Square & $\begin{array}{l}\text { Adjusted R } \\
\text { Square }\end{array}$ & $\begin{array}{l}\text { Std. Error of the } \\
\text { Estimate }\end{array}$ \\
\hline 1 & $.694^{\mathrm{a}}$ & .482 & .471 & 2.621 \\
\hline
\end{tabular}


Berdasarkan tabel di atas, diperoleh nilai $R$-square (koefisien determinasi) sebesar 0,482 maka dapat disimpulkan bahwa variabel kedisiplinan $\left(\mathrm{X}_{1}\right)$ dan kompensasi $\left(\mathrm{X}_{2}\right)$ berpengaruh terhadap variabel kinerja karyawan (Y) pada PT Mitra Pinasthika Mustika Rent sebesar $48,2 \%$ sedangkan sisanya 51,8\% dipengaruhi oleh variabel lain yang tidak diteliti dalam penelitian ini.

\section{Uji Hipotesis}

\section{Tabel 10. Hasil Uji t Kedisiplinan Coefficients $^{\mathrm{a}}$}

Unstandardized Coefficients

\begin{tabular}{ll|r|r|r|r|r}
\multicolumn{1}{l}{ Model } & \multicolumn{1}{c}{ B } & Std. Error & Beta & t & \multicolumn{1}{c}{ Sig. } \\
\hline \multirow{2}{*}{1} & (Constant) & 20.318 & 2.712 & & 7.491 & .000 \\
\cline { 2 - 7 } & Kedisiplinan (X1) & .495 & .070 & .579 & 7.029 & .000 \\
\hline
\end{tabular}

a. Dependent Variable: Kinerja Karyawan (Y)

Sumber : Data diolah (2020)

Berdasarkan tabel di atas diperoleh nilai $t_{\text {hitung }}>t_{\text {tabel }}(7,029>1.984)$, hal itu juga dibuktikan dengan signifikansi $0,000<0,05$. Dengan demikian maka $\mathrm{H}_{0}$ ditolak dan $\mathrm{H}_{1}$ diterima, hal ini menunjukkan bahwa terdapat pengaruh positif dan signifikan secara parsial antara kedisiplinan terhadap kinerja karyawan pada PT Mitra Pinasthika Mustika Rent.

Tabel 11. Hasil Uji t Kompensasi Coefficients ${ }^{\mathrm{a}}$

Unstandardized Standardized Coefficients Coefficients

\begin{tabular}{|c|c|c|c|c|c|c|}
\hline & \multirow{2}{*}{$\frac{B}{15.412}$} & \multirow{2}{*}{$\begin{array}{r}\text { Std. Error } \\
2.879\end{array}$} & \multirow{2}{*}{ Beta } & \multirow{2}{*}{$\frac{\mathrm{t}}{5.353}$} & \multirow{2}{*}{$\begin{array}{l}\text { Sig. } \\
.000\end{array}$} \\
\hline & $\begin{array}{l}\text { Model } \\
1 \quad \text { (Constant) }\end{array}$ & & & & & \\
\hline & $\begin{array}{l}\text { (Constant) } \\
\text { Kompensasi (X2) }\end{array}$ & 15.412 & .074 & .644 & 8.325 & .000 \\
\hline
\end{tabular}

a. Dependent Variable: Kinerja Karyawan (Y)

Sumber : Data diolah (2020)

Berdasarkan tabel di atas diperoleh nilai $t_{\text {hitung }}>t_{\text {tabel }}(8,325>1.984)$, hal itu juga dibuktikan dengan signifikansi $0,000<0,05$. Dengan demikian maka $\mathrm{H}_{0}$ ditolak dan $\mathrm{H}_{1}$ diterima, hal ini menunjukkan bahwa terdapat pengaruh positif dan signifikan secara parsial antara kompensasi terhadap kinerja karyawan pada PT Mitra Pinasthika Mustika Rent.

\begin{tabular}{|c|c|c|c|c|c|c|}
\hline & \multicolumn{6}{|c|}{$\begin{array}{c}\text { Tabel 12. Hasil Uji F Simultan } \\
\text { ANOVA }^{\text {A }}\end{array}$} \\
\hline & Model & $\begin{array}{c}\text { Sum of } \\
\text { Squares }\end{array}$ & $\mathrm{df}$ & $\begin{array}{c}\text { Mean } \\
\text { Square }\end{array}$ & $\mathrm{F}$ & Sig. \\
\hline 1 & Regression & 619.505 & 2 & 309.752 & 45.100 & $.000^{\mathrm{b}}$ \\
\hline & Residual & 666.205 & 97 & 6.868 & & \\
\hline & Total & 1285.710 & 99 & & & \\
\hline
\end{tabular}

a. Dependent Variable: Kinerja Karyawan (Y)

b. Predictors: (Constant), Kompensasi (X2), Kedisiplinan (X1)

Sumber : Data diolah (2020)

Dari tabel di atas, diperoleh nilai $\mathrm{F}$ hitung lebih besar dari $\mathrm{F}$ tabel atau $(45,100>$ 3.090), hal tersebut juga diperkuat dengan signifikansi $0,000<0,05$. Dengan demikian $\mathrm{H}_{0}$ ditolak dan $\mathrm{H}_{3}$ diterima. Artinya terdapat pengaruh positif dan signifikan secara simultan antara kedisiplinan dan kompensasi terhadap kinerja karyawan. 


\section{Kesimpulan}

Berdasarkan analisis serta pembahasan mengenai pengaruh kedisiplinan dan kompensasi terhadap kinerja karyawan karyawan, sebagai berikut :

1) Kedisiplinan berpengaruh positif dan signifikan terhadap kinerja karyawan dengan nila korelasi sebesar 0,579 artinya memiliki pengaruh yang kuat. Besarnya pengaruh sebesar $33,5 \%$. Uji hipotesis diperoleh $t$ hitung $>t$ tabel atau $(7,029>1,984)$, hal ini diperkuat dengan probability $0,000<0,05$, dengan demikian $\mathrm{H}_{0}$ ditolak dan $\mathrm{H}_{1}$ diterima artinya terdapat pengaruh yang positif dan signifikan antara kedisiplinan terhadap kinerja karyawan pada PT Mitra Pinasthika Mustika Rent.

2) Kompensasi berpengaruh positif dan signifikan terhadap kinerja karyawan dengan nilai korelasi sebesar 0,644 artinya memiliki pengaruh yang kuat. Besarnya pengaruh sebesar $41,4 \%$. Uji hipotesis diperoleh $t$ hitung $>t$ tabel atau $(8,325>1.984)$, hal ini diperkuat dengan probability $0,000<0,05$, dengan demikian $\mathrm{H}_{0}$ ditolak dan $\mathrm{H}_{2}$ diterima artinya terdapat pengaruh yang positif dan signifikan antara kompensasi terhadap kinerja karyawan pada PT Mitra Pinasthika Mustika Rent.

3) Kedisiplinan dan kompensasi berpengaruh positif dan signifikan terhadap kinerja karyawan dengan persamaan regresi $\mathrm{Y}=11,712+0,270 \mathrm{X}_{1}+0,448 \mathrm{X}_{2}$. Semakin tinggi kedisiplinan dan kompensasi maka kinerja karyawan karyawan juga akan semakin meningkat. Nilai korelasi atau tingkat hubungannya antara variabel bebas dengan variabel terikat diperoleh sebesar 0,694 artinya memiliki pengaruh yang kuat dengan kontribusi pengaruh secara simultan sebesar 48,2\% sedangkan sisanya sebesar 51,8\% dipengaruhi faktor lain. Uji hipotesis diperoleh nilai $F_{\text {hitung }}>F_{\text {tabel }}$ atau $(45,100>3.090$ dengan probability $0,000<0,05$. Dengan demikian $\mathrm{H}_{0}$ ditolak dan $\mathrm{H}_{3}$ diterima. Artinya terdapat pengaruh positif dan signifikan secara simultan antara kedisiplinan dan kompensasi terhadap kinerja karyawan karyawan pada PT Mitra Pinasthika Mustika Rent.

\section{Saran}

1) Variabel Kedisiplinan, pernyataan yang paling lemah adalah pernyataan nomor 10 yaitu 10 memiliki kesadaran yang tinggi terhadap pekerjaan dimana hanya mencapai score sebesar 3,62 meskipun termasuk dalam kategori baik namun untuk lebih baik lagi perusahaan harus menumbuhkan kesadaran pada seluruh karyawan agar memiliki etos kerja yang optimal.

2) Variabel kompensasi, pernyataan yang paling lemah adalah pernyataan nomor 5 yaitu Bonus yang diterima karyawan sudah sesuai dengan prestasi kerja yang dicapai dimana hanya mencapai score sebesar 3,65 meskipun termasuk dalam kategori baik namun untuk lebih baik lagi perusahaan harus memberikan bonus berdasar pada kesepakatan dalam aturan perusahaan.

3) Variabel kinerja karyawan, pernyataan yang paling lemah adalah pernyataan nomor 5 yaitu Perusahaan memberikan fasilitas yang baik untuk meningkatkan kinerja karyawan dimana hanya mencapai score sebesar 3,65 meskipun termasuk dalam kategori baik namun untuk lebih baik lagi perusahaan harus meningkatkan sarana prasarana dalam perusahaan agar mampu meningkatkan kinerja yang maksimal.

4) Kontibusi pengaruh antara kedisiplinan dan kompensasi secara simultan terhadap kinerja karyawan karyawan sebesar 48,2\%, nilai ini masih bisa ditingkatkan serta kondisi masing-masing variabel bebas harus ditingkatkan secara signifikan. Oleh karenanya disarankan kepada penelitian berikutnya agar melakukan penelitian yang relevan dengan cara memperbaiki indikator yang masih tidak baik atau dengan menambah indikator pertanyaan dan jumlah responden penelitian sehingga akan dapat lebih diketahui variabel yang paling memberikan kontribusi positif bagi perusahaan 


\section{Daftar Pustaka}

A.A Anwar Prabu Mangkunegara, (2014). "Sumber Kerangka Berfikir Kinerja". Gramedia, Jakarta Selatan.

Agung Nugroho, (2012). "Strategi Jitu Dalam Memilih Metode Statistik Peneltian", Andi, Yogyakarta.

Algifari, (2011). "Analisis Regresi", Yogyakarta.

Andi Supangat, (2014). "Statistika dalam Kajian Deskriftif, Inferensi dan Non Parametric", Edisi Pertama, Jakarta: Kencana Prenada Media Group,

Arikunto, Suharsimi, (2015). "Prosedur Penelitian Suatu Pendekatan Praktek", Jakarta: PT. Rineka Cipta.

Assagaf, Yusran, (2013). "Pengaruh Kompensasi Terhadap Kinerja Karyawan", Hasanudin, Makasar,

Athoillah, Anton, (2013). "Dasar-Dasar Manajemen", Bandung: CV Pustaka Setia.

Buchari, Zainun, (2015). “Manajemen dan Motivasi”, Jakarta: Balai Aksara.

Dessler, Gerry, (2014). "Human Resources Management", Prenticehall, International Inc, London.

Edi Sutrisno. (2012). "Sumber Daya Manusia", Surabaya: PT. Gramedia,.

Ghozali, Imam, (2014). "Aplikasi Analisis Multivariate dengan Program SPSS", Edisi Kelima, Badan Penerbit Undip, Semarang.

Guno, Tri dan Gering Supriyadi, "Kompensasi dan Organisasi Pemerintah", Modul Materi Diklat Penjabatan Golongan I dan II, Jakarta ,2012.

Hamlan Laly (2015) "Pengaruh Kompetensi, Disiplin kerja dan Kompensasi terhadap Kinerja Pegawai Badan Pemberdayaan Perempuan dan Keluarga Berencana Daerah Provinsi Sulawesi Tengah".

Hasibuan, (2016). "Sumber Daya Manusia”, , Jakarta: Haji Masagung.

Istijianto, (2012). “Aplikasi Praktis Riset Pemasaran”, Jakarta: Gramedia Pustaka Utama

J. Supranto, (2013). Statistik Teori dan Aplikasi, Edisi ketujuh Jilid 2: Jakarta.

Jonathan Sarwono, (2012). "Metode Penelitian Kuantitatif Dan Kualitatif”, Yogyakarta: Graha Ilmu,

Mardi Astuti (2016) “Pengaruh Kompensasi dan Disiplin Kerja terhadap Kinerja Karyawan”.

Mulyadi, (2015). "Manajemen Sumber Daya Manusia”, Jakarta: In Media.

Nawawi, Ismail, (2013). "Budaya Organisasi,Kepemimpinan, dan Kinerja", Jakarta: PT. Fajar Iterpratama Mandiri.

Oktriana Vetra Sari, Zunaidah (2015) "Pengaruh Kompensasi dan Lingkungan Kerja terhadap Kinerja para Pegawai Badan Penanggulangan Bencana Provinsi Sumetera Selatan”.

Priansa, Doni, Juni, (2014) "Perencanaan dan Pengembangan SDM", Bandung: Alfabet.

Putu Agus Candra Mahardika (2016) "Pengaruh Kompensasi dan Disiplin Kerja terhadap Kinerja Karyawan pada Hotel Puri Bagus Lovina".

Rivai, Veithzal, (2013). "Manajemen Sumber Daya Manusia Untuk Perusahaan", Raja Grafindo Persada, Jakarta.

Rivai, Vetizhal, (2014). “Kepemimpinan dan Kinerja Karyawan”, Bumi Aksara, Jakarta.

Santoso, Singgih, (2015). “SPSS Statistik Parametik” Cetakan Kedua, PT. Elek Media. 
Sarwono, Jonathan, (2012). “Metode Penelitian Kuantitatif Dan Kualitatif”, Yogyakarta: Graha Ilmu.

Singgih Santoso (2013). "SPSS Statistik Parametik" Cetakan Kedua, Jakarta: PT. Elek Media,

Sudaryono, (2017). "Pengantar Manajemen Teori dan Kasus, Yogyakarta : Caps.

Sudjana, (2011). "Metode Statistika", Edisi Keenam, Bandung: Tarsito.

Sugiyono, (2016). "Metode Penelitian Kuantitatif Kualitatif dan R \& D”, Bandung: Penerbit CV. Alfabeta.

Suherman, Wawan, (2012). "Kurikulum Berbasis Kompetensi Pendidikan Jasmani Teori dan Praktik Pengembangan", Yogyakarta: FIK UNY.

Supranto. (2013) "Statistik Teori dan Aplikasi", Jakarta: Pustaka Ekonomi,

Sutrisno, Edi., (2014). "Pengaruh Disiplin kerja dan Budaya Organisasi Terhadap Kinerja Karyawan Devisi Radiologi RSUD Karidi", Semarang Vol. 12 No.2.

Syofian Siregar, (2011). "Statistika Deskriptif Untuk Penelitian", Jakarta: PT Raja Grafindo Persada.

Taliziduhu, Ndraha. (2003). “Teori Budaya Organisasi”, Cetakan Kedua, Jakarta: PT Rineka Cipta.

Tika, Moh. Panbudu, (2010). "Budaya Organisasi dan Peningkatan Kinerja Perusahaan", Cetakan ke 3, Jakarta : Bumi Aksara.

Umam, Khaerul, (2015). "Manajemen Organisasi". Bandung : Pustaka Setia.

Yuningsih dan Keumala Hayati. (2008). "Faktor-Faktor Penentu Kompensasi", Universitas Lampung", 